\title{
The Science of Social Distancing and Total Lock Down: Does it Work? Whom does it Benefit?
}

\author{
Geofrey Musinguzi ${ }^{1,2 \star}$, Benedict Oppong Asamoah ${ }^{3}$
}

\author{
${ }^{1}$ Department of Disease Control and Environmental Health, Makerere University School of Public Health, UGANDA \\ ${ }^{2}$ Department of Primary and Interdisciplinary care, University of Antwerp, BELGIUM \\ ${ }^{3}$ Social Medicine and Global Health, Department of Clinical Sciences, Malmö, Lund University, SWEDEN \\ *Corresponding Author: mgeof@musph.ac.ug
}

Citation: Musinguzi G, Asamoah BO. The Science of Social Distancing and Total Lock Down: Does it Work? Whom does it Benefit?. Electron J Gen Med. 2020;17(6):em230. https://doi.org/10.29333/ejgm/7895

\begin{tabular}{|c|c|}
\hline ARTICLE INFO & ABSTRACT \\
\hline Received: 2 Apr. 2020 & COVID-19 is spiralling like wild fire and has caused a global mayhem. Many lives have already been lost, and the \\
\hline Accepted: 5 Apr. 2020 & $\begin{array}{l}\text { global economy is at stake. In the absence of vaccine, social distancing and total lock down is the current mainstay } \\
\text { in efforts to mitigate and flatten the epidemic curves. Several countries across the globe are currently } \\
\text { implementing social distancing and total lock downs. However, what is social distancing and lock down? Does it } \\
\text { work? Whom does it benefit? We expound on these questions and conclude that social distancing and lock down } \\
\text { benefit the local and international community alike. Moreover, we hypothesis that evacuations may facilitate } \\
\text { international spread of a highly contagious disease of pandemic potential. }\end{array}$ \\
\hline
\end{tabular}

Keywords: social distancing, total lock down, COVID-19, SARS-COV 2

\section{BACKGROUND}

COVID-19 is spiralling like wild fire and has caused a global mayhem (1). Many lives have already been lost, and the global economy is at stake. From Far East Asia through Europe and Africa to the far West coast of the Americas, countries are struggling with measures to slow the progression of COVID-19 pandemic. The outbreak started from Wuhan in Hubei Province in China, an area with a full time population of $>9$ million and a transient population of $>5$ million (2). Wuhan is a major transport hub in central China, linking road, rail and air transport, locally and internationally. At the time of the outbreak, the Chinese New Year and a holiday was in the offing. About five million of the transient population left (or planned to leave) for the New Year or for holidays (3). However, evidence suggest that some left because of the lingering epidemic (2). Moreover, delays in notification were also reported. This setting provided a perfect launch pad for an infectious disease of pandemic potential and containment at source became impossible $(2,4)$.

\section{HOW IT ALL STARTED}

In December 2019, a cluster of patients presenting with pneumonia like symptoms were reported in Wuhan, China. The cases were later linked to a Wuhan Seafood wholesale Market (3). Following a launch into the cause of the pneumonia, a new virus - Severe Acute Respiratory Syndrome known as SARS CoV-2 related to bat coronaviruses and pangolin (a wild animal) coronaviruses were identified as the causative agents of the pneumonia like symptoms (5). On $31^{\text {st }}$ December 2019, the outbreak was officially reported and measures to contain the virus were swung in action. Due to the virulence and the rate of transmission, Wuhan was locked down on January 23, 2020, to enhance social distancing and limit transmission of COVID-19. Schools, universities, businesses and public transport were shut $(2,4)$. However, it appears that these measures were instituted several days or weeks late - thus, resulting in a missed opportunity to contain the virus at source (4). Of the more than 14 million people, about 5 million left Wuhan before the stringent measures started - effectively siphoning the virus out of Wuhan and eluding lock down efforts to localise the epidemic and maximise containment (4).

\section{THE LOCK DOWN AND HOW SOCIETY RESPONDED}

Effective $23^{\text {rd }}$ January 2020, Wuhan residents were not allowed to leave the city any more and more stringent lockdown measures were instituted in the following weeks with residents not allowed to leave their homes except with permission. By end of January, more than 10 million people were confined to their homes in a bid to contain the outbreak. These residents had no other options but to stay in their homes till the end of the quarantine. Pien Huang notes that a transition characterised by panic, fear and then acceptance describes the residents' experiences during the lock down in Wuhan. On the other hand, the international response to the lock down was a bargain by several foreign governments to evacuate their nationals from the hot bed to "safe havens" - 
their home countries. Indeed several countries succeeded in airlifting and evacuating their citizens during the Wuhan lockdown. Is it possible that this response contributed to the international spread of COVID-19? Did we do enough to contain the virus at source as an international community? Should we have done otherwise, maybe provided more support locally? Did we miss an opportunity and instead created more problems? These are all questions that still linger on in the midst of this global pandemic among the global community including scientists and the policy environment. Reliable answers are needed to these questions to create a platform for pro-active action now and in the future.

\section{THE SCIENCE OF SOCIAL DISTANCING AND LOCK DOWN, DOES IT WORK?}

Social distancing is a deliberate effort instituted to stop or slow down the spread of a highly infectious or contagious diseases. The measures may involve closing partially or wholly social activities including business, transport, among others that may enhance social contact and propagate spread. In Wuhan, more than 10 million people were restricted to their homes. Evidence from the city suggests that the COVID-19 exponential transmission trajectory was interrupted and the curve was slowed and finally flattened (6). Fatality, though, initially high was quickly slowed down. New cases of COVID-19 were halted. In their paper, Prem et al, concludes that the unprecedented measures that the city of Wuhan instituted helped to break the back bone of the epidemic (6). They argue that whether the curve will remain flattened or not will depend on the next steps following the lifting of the lock down in the city of Wuhan. Nevertheless, Wuhan has provided a vital learning curve for other countries battling the epidemic. On the other hand, though evidence is lacking, we cannot rule out the likelihood that evacuations contributed to global spread of the virus given that up to $80 \%$ of COVID-19 exposed may only present mild or no symptoms. Moreover, the diagnostic capability only evolved later. During the 1918/19 Influenza A1H1N1 Pandemic, social distancing played a critical role. The pandemic which started in Spain was mild at its onset; became virulent and led to approximately 300 million cases and about 50 million deaths globally [4]. Response to this pandemic also varied across the globe. Incidentally, social distancing measures and total lock down were the main stay in flattening the epidemic curves. Like COVID-19, the 1918 Influenza A H1N1 pandemic had no vaccine and treatment. Thus, countries focussed on preventive measures with social distancing and lock downs as the most reliable measures to contain the spread. The classic example of these measures are best demonstrated across the different federal states in the United States of America. In an article published by Strochlic and Champine, they show that St. Louis instituted strong social distancing measures early enough and managed to minimise transmission compared to Philadelphia which only instituted strict measures after the death rates had started to rise. They show that deaths due to the virus were estimated to be about 385 people per 100,000 in St Louis, compared to 807 per 100,000 in Philadelphia during the first six months, which were the deadliest period of the pandemic (7). They conclude by stating that social distancing saved thousands of American lives during the 1918/19 pandemic. Cities that implemented social distancing measures early enough were more effective in their prevention efforts against the 1918/19 influenza H1N1 pandemic.

\section{SO, WHOM DOES SOCIAL DISTANCING BENEFIT}

Social distancing "recently described as physical distancing" is beneficial to the local population - the epicentre of the epidemic but also benefits national and global communities. At the local level, when social distancing is achieved early enough, fewer people may get infected - thus, healthcare is not excessively strained and local demand is served better. Otherwise, when transmission is not curtailed, and the spread skyrockets, healthcare system become overwhelmed and as a result, some patients inevitably go through unattended to. We have observed these stretching scenarios already in the UK, Italy, Spain and other countries across the globe. Therefore, social distancing allows for the critical time required to build the capacity of health care systems to ably respond to the epidemic. At the national level, sufficient time for planning and resources mobilisation is feasible if the disease is contained locally through social distancing efforts. National resources are maximised to contain the outbreak at source. At the global level, a pandemic may be avoided enabling global resources to be harnessed to deal with the epidemic at the source. Moreover, global economic meltdown and other social disruptions may be avoided - thus benefiting the broader global community.

\section{LIMITATIONS}

This perspective is limited by the currently inadequate data on social distancing in the context of COVID-19. Although several countries across the globe have now instituted social distancing and lock down measures, the challenge is how to eventually end these measures without undoing current gains. We know that social distancing measures are time sensitive given that other societal aspects of livelihood and wellbeing get severely constrained. Unfortunately, little is still known about COVID-19. There is still uncertainty on the relationship between seasonality and infectiousness of COVID-19 (8). Thus, in the event that social distancing and lock down measures may be prolonged, it is vital to ensure that the communities are prepared to handle prolonged periods of isolation and shortages in the supply of essential commodities. Failing to have alternative plans for such prolonged measures could lead to harsh adverse effects on the community and may subsequently kick-in another wave of the epidemic or even other disease outbreaks. Thus, as pointed out in the study by Prem et al. careful consideration of epidemiological and modelling evidence is needed before lifting these measures to mitigate the impact of a second peak (6). Moreover, lifting may require to be conducted gradually in a staggered manner.

\section{CONCLUSION}

For an infectious non-discriminatory virulent disease, social distancing and lock downs benefit the local and the international community - and thus require that all players at the local and international level work together to contain the 
epidemic. Social distancing and lock down may not be desirable but may prevent local and global spread of contagious diseases. Whereas evacuations may work in combat zones, they may facilitate transmission of infections across borders to the regret of the broader global community.

\section{REFERENCES}

1. Cakir Z, Savas H. A Mathematical Modelling Approach in the Spread of the Novel 2019 Coronavirus SARS-CoV-2 (COVID19) Pandemic. Electron J Gen Med. 2020;17(4):em205. https://doi.org/10.29333/ejgm/7861

2. Fan J, Liu X, Pan W, Douglas M, Bao S. Epidemiology of 2019 Novel Coronavirus Disease-19 in Gansu Province, China, 2020. Emerging Infectious Diseases. 2020;26(6). https://doi.org/10.3201/eid2606.200251 PMID:32168465 PMCid:PMC6924917

3. Li Q, Guan X, Wu P, Wang X, Zhou L, Tong Y, et al. Early transmission dynamics in Wuhan, China, of novel coronavirus-infected pneumonia. New England Journal of Medicine. 2020. https://doi.org/10.1056/NEJMoa2001316 PMID:31995857
4. Chen S, Yang J, Yang W, Wang C, Bärnighausen T. COVID-19 control in China during mass population movements at New Year. The Lancet. 2020;395(10226):764-6. https://doi.org/10.1016/S0140-6736(20)30421-9 PMID: 32105609

5. Munster VJ, Koopmans M, van Doremalen N, van Riel D, de Wit E. A novel coronavirus emerging in China-key questions for impact assessment. New England Journal of Medicine. 2020;382(8):692-4. https://doi.org/10.1056/ NEJMp2000929 PMID:31978293

6. Prem K, Liu Y, Russell TW, Kucharski AJ, Eggo RM, Davies N, et al. The effect of control strategies to reduce social mixing on outcomes of the COVID-19 epidemic in Wuhan, China: a modelling study. The Lancet Public Health. 2020. https://doi.org/10.1016/S2468-2667(20)30073-6 PMID: 31978293

7. Strochlic N, Champine RD. How some cities 'flattened the curve' during the 1918 flu pandemic. 2020. Available at: https://www.nationalgeographic.com/history/2020/03/ho w-cities-flattened-curve-1918-spanish-flu-pandemiccoronavirus/

8. Gondauri D, Mikautadze E, Batiashvili M. Research on COVID-19 Virus Spreading Statistics based on the Examples of the Cases from Different Countries. Electron J Gen Med. 2020;17(4):em209. https://doi.org/10.29333/ejgm/7869 